\title{
Conceptual Analysis and Empirical Observations of Animal Minds
}

\author{
Ricardo Parellada ${ }^{1}$ \\ Received: 17 September 2020 / Revised: 14 January 2021 / Accepted: 24 January 2021 / \\ Published online: 11 February 2021 \\ (c) The Author(s) 2021
}

\begin{abstract}
The relation between conceptual analysis and empirical observations when ascribing or denying concepts and beliefs to non-human animals is not straightforward. In order to reflect on this relation, I focus on two theoretical proposals (Davidson's and Allen's) and one empirical case (vervet monkeys' alarm calls), the three of which are permanently discussed and considered in the literature on animal cognition. First, I review briefly Davidson's arguments for denying thought to non-linguistic animals. Second, I review Allen's criteria for ascribing concepts to creatures capable of correcting their discriminatory powers by taking into account their previous errors. Allen affirms that this is an empirical proposal which offers good reasons, but not necessary or sufficient conditions, for concept attribution. Against Allen, I argue that his important proposal is not an empirical, but a conceptual one. Third, I resort to vervet monkeys to show that Allen's criteria, and not Davidson's, are very relevant for ascribing first-order and denying second-order beliefs to this species and thus make sense of the idea of animal cognition.
\end{abstract}

Keywords Animal mind · Animal cognition · Conceptual analysis · Empirical investigation · Colin Allen · Donald Davidson

\section{Concepts and Experience}

The interdependence of concepts and observations when studying animal minds is clearly stressed by important contributions in the field. The need for both theoretical analyses inspired by the philosophy of mind and action and empirical investigations in nature and the lab, stemming from different scientific approaches, is constantly present, for instance, in the joint books, edited books and papers by Colin Allen, the philosopher, and Mark Bekoff, the cognitive ethologist. "The

Ricardo Parellada

parellada@ucm.es

1 Department of Logic and Theoretical Philosophy, Complutense University of Madrid, Madrid, Spain 
heart of Allen and Bekoff's book-reads the editorial description of their 1997 Species of Mind-is this reciprocal relationship between philosophical theories of mind and empirical studies of animal cognition. The interdisciplinary approach reveals flaws in common objections to the view that animals have minds." They stress from the outset "the need for interdisciplinary connections between empirical and theoretical approaches" (ix), which goes into the title of their 2002 important collection, edited with Gordon Burghardt, The Cognitive Animal. Empirical and Theoretical Perspectives on Animal Cognition (Bekoff et al. 2002).

In his book on what animals can know about conspecifics' psychological states (the problem of mindreading or theory of mind), Robert Lurz highlights precisely these as key issues and organizes his investigation and his proposals around them: "It became clear to me, after much study, that there were two fundamental issues that defined the debate: (i) how best to conceive of mental state attribution in animals and (ii) how best to test for it empirically. And I soon became dissatisfied with the answers that philosophers and scientists tended to give to (i) and (ii)" (Lurz 2011, xi). Martínez Freire sees animal minds as a crucial topic for "the continuity between science, where the bedrock is experimental knowledge, and philosophy, characterized by conceptual analysis" (2008, 2009, 445).

On her side, in her recent comprehensive book The Animal Mind. An Introduction to the Philosophy of Animal Cognition, Kristin Andrews stresses the mutual feedback between concepts and observations, argues that empirical results can refute metaphysical or apriori treatments and urges both conceptual and empirical work: "Justification for the existence of some psychological property in animals should come from a convergence of good empirical evidence and careful conceptual analysis, and this is also true for cognitive capacities such as mindreading" (2015, 163). She stresses this point from the beginning of her book, and illustrates it with a psychological property I will not consider in this paper, i. e. consciousness. Her argument is worth reading in full.

The philosopher's analysis of concepts is first fed by what she sees in the world, and then again by how the world behaves once it is seen through the theoretical lens. For example, suppose we understand consciousness as necessarily involving the ability to feel pain, and evidence of feeling pain comes from observing irritant responses, such as shrinking back from a pinprick or a hot stove. We can use this simple account to investigate the distribution of consciousness, and find that a meditating monk doesn't react to a pinprick, and a mimosa plant will close its leaves when brushed-but doesn't respond after being given an anesthetic that eliminates pain responses in humans. Given other reasons we have for thinking that the monk is conscious (say, her verbal report), and other reasons for thinking that plants don't experience pain (say, our identification of pain as being caused by neural structures that are absent in plants), we can modify our understanding of consciousness slightly, and use the new understanding to investigate the world again, which may lead to a further revision of the concept. This constant calibration of concepts and observations means that no simple answer is 
going to be available to any of the questions asked in this book. (Andrews 2015, 3).

The relation between conceptual and empirical approaches to animal cognition is tricky. In this paper, I do not deal with this problem in a general way, but I do intend to examine a specific controversy under this perspective. Many animals are capable of engaging in novel, not merely repetitive behaviors, and of learning from their mistakes. But this fact is interpreted in very different ways, depending on the type of beliefs or cognitive abilities that are attributed to animals. On the one hand, for example, Donald Davidson's position is well-known. He maintains that languagelacking animals cannot have beliefs or mental states in general because these states involve conceptual and propositional knowledge and require the presence of many other beliefs (due to the holism of the mental) that it would be arbitrary to suppose in animals. On the other hand, for instance, Colin Allen stresses the need to introduce actual psychological elements in order to interpret the plasticity of some animals' behavior and their ability to learn from their mistakes, beyond perception or reactions to current stimuli. After examining these two positions, I will resort to well-known empirical observations about vervet monkeys' alarm calls. I argue that this case study can be much better described with Allen's than with Davidson's conceptual proposals. The former invites us to attribute some beliefs and to deny others to the same species, vervet monkeys, and this controversy enriches our understanding of the relation between concepts and observations.

\section{Animal Beliefs and Concepts: Donald Davidson's Conceptual Analysis}

Davidson certainly admits that many animals can discriminate between different kinds of prey, predatory strategies, hiding places. At their best, these animals can also learn from their individual mistakes to fine-tune their subsequent behaviors. The point of Davidson's proposal lies in the conceptual reading or interpretation of these behaviors. To describe them we use psychological or mentalistic terms: the dog believes that the cat has climbed the tree, wants to reach it, gets angry because it cannot climb... We naturally describe the behavior of animals with these psychological terms. But, if it is difficult to imagine the subjective experiences of other people — which we do based on their behavior and our own experiences-it will be much more so in the case of animals (Nagel 1974). Now, Davidson's argument is not based on our difficulty to imagine the subjective experiences of animals, but on the difficulty of attributing these experiences to them when we analyze what they consist of.

According to Davidson, every belief (generic term for propositional attitudes) is characterized by its propositional content, and to conceive this propositional content one must start from the concepts that take part in it. To believe that a cat has climbed a tree, it would not be enough to scratch its trunk and bark upwards, but it is necessary to know, somehow, what a cat is and what a tree is, that is, to possess the concepts of cat and tree. In order to have the cat concept, continues Davidson, it 
is not necessary to have a unique or specially defined concept, but it is that this concept includes some minimal features, such as that it is a living being, that it usually runs from one side to another and that it is able to climb trees. And, to believe that the cat has climbed the tree, it is also necessary to have numerous associated beliefs, such as that this tree is the same as yesterday's, or a new one that is elsewhere... According to this analysis, having a belief presupposes having many other beliefs and mastering a certain amount of concepts (Davidson 1975, 1982).

The reason neither a dog nor any other creature can have a single belief, such as that it is seeing a cat, is that what identifies a belief is what we loosely call its propositional content. Thus to have a belief about a cat, one must have mastery of the concepts that are involved in this judgment or belief. A creature does not have the concept of a cat merely because it can discriminate cats from other things in its environment. (Davidson 1999, 8).

In an additional demanding step, Davidson affirms that in order to have a belief it is not only necessary to have many others (holism of the mental), but also to possess the concept of belief and objective truth. And that to possess the concept of belief, language is necessary, so in the case of subjects without language, despite the fact that we describe their behavior naturally with psychological and intentional terms, the attribution of a single belief would force us to attribute to them many others and many concepts that we do not even know how to begin to make sense of.

Much of the point of the concept of belief is that it is the concept of a state of an organism which can be true or false, correct or incorrect. To have the concept of belief is therefore to have the concept of objective truth. If I believe there is a coin in my pocket, I may be right or wrong; I'm right only if there is a coin in my pocket. If I am surprised to find there is no coin in my pocket, I come to believe that my former belief did not correspond with the state of my finances. I have the idea of an objective reality which is independent of my belief. (Davidson 1982, 326).

Accordingly, in order to believe something about the world around us it is necessary to know that we can be wrong, that is, that although we may have believed to see a cat, it may have been a bush moved by the wind. In order to believe it, it is necessary to know that the belief can fail; in order to know that a belief is fallible, it is necessary to have the concepts of belief and truth independent of us. So, according to Davidson's analysis, to have a belief it is necessary to have other beliefs, the concept of belief and the notion of truth, so it is more than doubtful that we can attribute any type of beliefs, thoughts or intentional states to animals lacking language (Davidson 1982, 1999).

Davidson's conceptual arguments are sometimes called metaphysical or apriori claims (Andrews 2016, 19; Glock, 2017). The important point is that these are all ways to oppose them to empirical research and findings. Unsurprisingly, these arguments are widely rejected and even derided by cognitive ethologists, but it must be said that these scientists usually do not really engage with them. Two serious philosophical attempts to meet Davidson' reasoning are Chadha (2007) and Glock 
(2017). They are both empirically informed pieces, but they also address Davidson's conceptual analysis in its own terrain. I do not intend to review these criticisms, but to present the contrast between concepts and experience from a different angle.

At one point, Kristin Andrews affirms that Davidson's "metaphysical claims" have been falsified by empirical research. I think the issue is not correctly put this way. In my opinion, the point is rather that the concepts involved are subject to refinement and even modifications, in part due to their adequacy or inadequacy to grasp and describe new and old experiences. Andrews herself explains it nicely in the passage I quoted in the previous paragraph, and also in the following one: "While many philosophers agree that animals have concepts, belief, or rationality, their reasoning for these conclusions takes very different forms. And what they mean by concepts, belief, or rationality likewise varies. Apparent agreement on the question 'Do animals have beliefs?' may be deceptive" (Andrews 2015, 109). In the next paragraph, I will present a well-known proposal by Colin Allen about how to conceive of and attribute psychological properties to animals. He terms it an empirical proposal, but I will argue that it is rather conceptual, one of those cases in which the understanding of concepts and beliefs varies, in Andrews terms.

\section{Concepts and Behaviors: Colin Allen's Conceptual Analysis}

In a series of single authored and co-authored papers and books-some with cognitive ethologist Marc Bekoff-Colin Allen has offered important proposals and presentations of the state of art in animal cognition. I will focus on his 1999 proposal of three criteria for concept attribution to animals, because it is very specific, it has been repeatedly revisited and discussed by Allen and others, and it is especially relevant for the question addressed in this paper: the relation and interdependence between concepts and experience. Allen presents a concrete proposal to attribute conceptual capacities to animals based on their ability to detect and correct their own mistakes. It reads as follows:

An organism $\mathrm{O}$ may reasonably be attributed a concept of X (e.g., TREE) whenever:

(i) systematically discriminates some Xs from some non-Xs; and

(ii) is capable of detecting some of its own discrimination errors between Xs and non-Xs; and

(iii) is capable of learning to better discriminate $\mathrm{Xs}$ from non-Xs as a consequence of its capacity (ii). (Allen 1999, 36-37).

Colin Allen presents this as an empirical proposal, as the title of his article clearly states: "Animal concepts revisited: the use of self-verification as an empirical approach". On the other hand, he affirms that this proposal does not amount to a philosophical analysis of what it is to possess a concept, but rather offers criteria so that it is reasonable to attribute some organisms internal states that can be called concepts. In Allen's opinion, it is reasonable to consider them as internal conceptual states because they cannot be explained by purely perceptual experiences or by the presence of stimuli. Allen proposes to understand them in psychological terms and 
to consider them animal concepts, although they do not exactly match the terms with which we analyze the propositional content of the mental states of human beings. He points out that it can be empirically verified whether or not the behavior of different animal species meets the proposed criteria.

Interestingly, Allen resorts to a striking analogy in order to illustrate the exact character and scope of his claims. With the above criteria, he does not intend to provide a philosophical analysis of what it is for an organism to possess a concept, but rather "good evidence" and "good grounds" for us to suspect that animals that meet the criteria might have concepts:

Meeting conditions (i)-(iii) above may provide good grounds for attributing concepts to animals, even though these conditions need be neither necessary nor sufficient for concept possession, just as finding a victim's blood on a pair of socks may provide good grounds for believing the sock owner to be a murderer even though blood on sock is neither a necessary nor sufficient condition for being a murderer. (ibid., 37).

He emphasizes this point by referring to his 1997 joint book with Bekoff. The blood-in-socks analogy is to be taken at face value:

It is important to be clear that the purpose of these three clauses is not to provide a philosophical analysis of what it is for an organism to possess a concept. The question of when it is reasonable to attribute a concept to an animal is a distinct question from that of what it means for an animal to possess a concept, just as the question of when it is reasonable to believe that someone is a murderer differs from the question of what it means to be a murderer. (ibid., 37).

Now, in my opinion, we can identify two major claims by Allen: (1) his three conditions do not offer philosophical analysis, but good grounds for concept attribution to animals; (2) his proposal is empirical. On the contrary, I argue that the statement that an organism $\mathrm{O}$ may reasonably be attributed a concept whenever three specific empirical conditions are met is an important conceptual proposal for how to conceive of animal concept possession.

To begin with, Allen makes a distinction between what it means for an animal to possess a concept (a matter of analysis) and when concept attribution to animals is reasonable (the matter of his proposal). He also explains that his conditions "need be neither necessary nor sufficient for concept possession", thereby implying, it seems, that this is what philosophical analysis should provide. Indeed, the identification of necessary and/or sufficient conditions for the application of a concept is a form of analysis, but it is not the only one. There are more and less stringent ways of providing conceptual work, a central philosophical endeavor. A review of different ways of understanding conceptual analysis would be out of place here, but I do want to mention three points that I believe can help the purpose of this paper: (1) kinds of conceptual work, (2) kinds of concepts to be analyzed, (3) relation between concepts and experience. 
In the first place, a terse summary is perhaps more useful than none. Classical logic understands the analysis of a concept as the determination of its place in the tree of knowledge, by means of genus and differentia specifica. Traditionally, when analysis determines essential features, it yields a real definition (rational animal). When it furnishes non-essential features that allow to discriminate objects from other classes, we have a nominal definition (featherless biped). The difficulty of distinguishing essential from non-essential characteristics leads to the clarification of concepts with necessary and sufficient conditions for their application. The demandingness of necessary and sufficient conditions can be deflated by providing necessary or sufficient conditions, which certainly advances our understanding. Under special circumstances or persuasions, conceptual analysis is a modest preparation for a higher philosophical accomplishment: eidetic intuition. From another viewpoint, meaning is use.

In the case we are dealing with, even though we lack an understanding, an insight or a thorough analysis of the notion of animal cognition or concept possession, the point of Allen's criteria is whether error correction independent of perception reasonably leads us to postulate an additional psychological element that it would be odd to understand but in conceptual terms. Should this be the case, these animal psychological capacities would demand the widening of cognitive or conceptual capacities from fine-grained propositional conceptualization that can be rendered in linguistic terms. Although Allen makes a sharp distinction between philosophical analysis and good grounds for concept attribution to animals, I wonder whether there is a great difference between providing good grounds or sufficient conditions.

In my view, the latter corresponds to the actual way Allen presents the matter in the abstract and the last page of his paper, which seem places for actual commitment. In the abstract, Allen states twice that he "argues" for animal concept ascription: "I argue for a three-part approach to attributing concepts to animals. The approach goes beyond the usual discrimination tests by seeking evidence for selfmonitoring of discrimination errors. Such evidence can be collected without relying on language and, I argue, the capacity for error-detection can only be explained by attributing a kind of internal representation that is reasonably identified as a concept." (ibid., 33, emphasis added). In the last page, he rewords the fundamental proposal of his paper as his claim: "The internal states implicated in the explanation of these capacities are worthy of being designated as concepts. For these capacities to be implemented it appears that there must be an internal standard of comparison that represents the organism's world independently of its perceptual representation at any given moment. Thus, such evidence supports the claim that organisms with these capacities possess representations of the world that are detached from immediate perceptual information." (ibid., 39).

In my opinion, Allen's proposal, claim or thesis makes fuller sense if his three criteria or conditions are actually meant to propose sufficient conditions for concept ascription. But, whether these good grounds for animal concept amount to sufficient conditions or not, my point is that, in either case, they deliver conceptual work, as I will try to show in the next two points.

In the second place, the different ways of understanding conceptual work depend not only on philosophical perspectives, but also, importantly, on the kinds 
of objects we are dealing with. Mathematical objects allow not only sharper, but also stipulative and genetic definitions. Natural, scientific, ordinary or moral concepts call for different conceptual approaches and allow for different kinds of evidence, such as scientific data, conventions or stipulations. To mention just one example, if we are working out a distinction between, say, sympathy and empathy, within a phenomenology of emotions, it would be odd to appeal to not experienced distinctions, such as the kind of neurons involved in such emotions.

For a different kind of concept, both ordinary and scientific, this is precisely the sort of information Kristin Andrews mentions in the paragraph I quoted at the beginning of this paper. As she says, our initial attribution of consciousness to a plant that reacts to certain stimuli can be reasonably corrected by our actual knowledge that such capacity is not possible for an organism without a nervous system. Andrews offers this correction as an example of "constant calibration of concepts and observations", that is, the question of what is consciousness is calibrated with the empirical evidence that, for all we know, organisms without a nervous system cannot be conscious. This example shows that natural and scientific concepts are open to adjustment both with neighboring concepts and with empirical evidence that may turn out to be relevant. In the case we are dealing with, Allen's proposal would be open to a similar correction of his behavioral conditions, should science offer, for instance, a physiological limit for extending animal psychology beyond perception. At the moment, nothing seems to forbid this extension. Allen's is precisely a sound way of pointing at that unknown terrain.

On the other hand, if different kinds of concepts call for different approaches, then Allen's murder analogy seems inadequate. Blood in socks may be good grounds for murder suspicion, although they have nothing to do with the question of what murder is. We are acquainted with the concept of murder. Socks are irrelevant for such concept, but may provide evidence for the existence of murder. On the contrary, Allen's behavioral conditions are precisely a way of making sense of the concept or animal cognition. We are not previously acquainted with this concept, we do not know what it is and whether the thing exists. Allen proposes no less than a way of making sense of it. Of course, his conditions do not provide a full analysis, but it seems reasonable that we credit an organism that meets those conditions with psychological capacities that go beyond perception. The proposal leaves open other approaches to animal cognition. That is why it offers sufficient, not necessary conditions.

In the third place, it is worth stressing the distinction between concepts and experience. In my opinion, "O systematically discriminates some Xs from some non-Xs" (condition (i)) is an empirical question; "O is capable of detecting some of its own discrimination errors between Xs and non-Xs" (condition (ii)) is an empirical question"; "O is capable of learning to better discriminate Xs from non-Xs as a consequence of its capacity (ii)" (condition (iii)) is also an empirical question. However, "An organism O may reasonably be attributed a concept of X (e.g., TREE) whenever [(i)-(iii) are met]" is a conceptual proposition. We can say it offers conceptual analysis or simply conceptual work on animal cognition. But, given the fact that we do not know whether the object (animal thought, animal concept possession) of the concept exists, it is perhaps 
better to call it a conceptual proposal. Allen suggests that, whenever conditions (i)-(iii) are met, it is reasonable to say that those creatures (should they exist) have some psychological capabilities that it is sound to call "concepts," such as the concept of tree, despite the fact that we cannot talk to them. I take this to be the crux of his argument.

Thus, Allen makes a theoretical or conceptual proposal for the attribution of concept possession to animals under certain conditions. The empirical relevance of this proposal is that the three criteria are susceptible of empirical verification for different species and behaviors. Although Allen usually illustrates his points with specific cases, in the text in which he makes this proposal he does not offer many examples of animal behavior that meets all three criteria and would thus be appropriate for concept attribution to animals. The fact that Allen does not here dwell on animal behavior that meets these criteria does not remove an iota of relevance to his proposal. On the contrary, in my opinion, it reveals its conceptual nature and it allows it to be better compared to other alternative proposals.

As we have seen, Davidson denies that non-linguistic animals have beliefs and concepts because they would have to master an entire network that would include the concepts of belief and truth themselves. For his part, Allen proposes three criteria to attribute concepts to animals, based on the ability for error detection and behavior correction without resorting to new stimuli or perceptions. Allen's is a theoretical proposal for the enlargement of our understanding of concept possession, when it would be odd to understand the psychological capacities he points at in other terms. Of course, it is an empirical question whether and which animal species should show these capacities. Davidson's is a more demanding theoretical proposal for concept possession and the analogous empirical question is which animal species meet his criteria. Our issue is how to better understand, distinguish and conceive of the varied psychological animal capacities. But this controversy seems to have an important bearing also in issues in human cognition, should Davidson's linguistic requirements implausibly speak against concept and belief ascription to humans with linguistic impairments (see Andrews 2002, on autism).

In sum, to stick to the topic of animal cognition, empirical research on psychological and behavioral capacities offered by cognitive ethology helps to specify, illuminate and complete theoretical proposals. However, empirical observations do not by themselves allow us to settle, strictly speaking, a conceptual question such as whether it is more appropriate to conceive of the psychological and conceptual possibilities of animals from Davidson's or Allen's proposal, that is, whether we should think that no belief or concept is possible for someone who does not have the concept of belief and others which are necessary to discursively display its propositional content; or, on the contrary, whether we must think a type of beliefs and concepts based on learning and selfcorrection independently of perception. Nevertheless, although the empirical results do not by themselves settle the theoretical discussion, they can provide precise and real situations and case studies that can be better understood and accounted for with one or other of the theoretical alternatives. To see how they can do this, I will consider a paradigmatic example. 


\section{Beliefs and Concepts in Concrete Behaviors: Vervet Monkeys}

Let us first look at a simple example of instinctive behavior that does not require the attribution of any mental state to animals. Some ants take their dead mates out of the anthill so they don't become infected. However, ants detect the death of their companions exclusively by the acid they give off, and are not able to distinguish a dead ant from a living one that has been impregnated with the same acid. Thus, ants depend on the presence of this perceptual stimulus and it is not necessary to suppose that they possess any mental state or any concept of death to explain their behavior (Allen 1999, 36). It is an instinctive behavior, encoded in their genes, more characteristic of the species than of individuals.

The case of vervet monkeys is more complex. In a series of papers and books (occasionally with other researchers), Robert Seyfarth and Dorothy Cheney have presented and revised empirical observations that have become "classic case-studies" (Gensini 2018) for the discussion about the attribution of beliefs and concepts to animals (Seyfarth et al 1980; Seyfarth and Cheney 1992, 2015; Cheney and Seyfarth 1990, 1996, 2007). Vervet monkeys use three different alarm calls when they spot a predator. When a vervet detects the presence of a leopard, it emits a signal and its companions become safe by climbing the trees. When it sees an eagle, it issues a different signal and its companions look at the sky and hide in the bushes. And when it sees a snake, it casts a third kind of signal and other monkeys stand on their hind legs and observe the herbage.

It has been observed that young monkeys sometimes err in their alarm signals and in their detection of the predator and that over time they learn to improve in both tasks. Monkeys have also been observed to sometimes issue false signals, for example when they want to trick a rival group. It has also been observed that monkeys gradually stop paying attention to the individual who repeatedly emits false alarms. As Achim Stephan points out, to display these behaviors, at least an operational distinction between the true and the false seems to be necessary, and these behaviors seem to meet Allen's conditions for the attribution of concepts to animals (Stephan 1999b, 87). Indeed, they distinguish different kinds of predators, detect their errors, and correct their signals in light of previous errors, not of new perceptual stimuli. Allen briefly refers precisely to vervet monkeys to point out that individual differences in detecting predators and other behaviors cannot be explained by appealing only to perceptual experiences (Allen 1999, 35).

Now, Seyfarth and Cheney have also carried out other research aimed at checking whether vervet monkeys and baboons have any kind of belief or awareness about the mental states of their companions. This further psychological capacity is called mindreading by philosophers and theory of mind by psychologists (Andrews 2015, 140). Results are completely different from the case of belief and concept attribution without intentional ascent. Individuals who could clearly see that other individuals were exposed to or deprived of certain information did not become really aware of the new state of knowledge of their peers. Even the mother who had been able to clearly see that her son had perceived food or had seen an enemy, continued to warn her offspring with exactly the same screams 
as if she had no information about what her son had seen. According to Cheney and Seyfarth's observations, vervets, baboons and other animals do not seem to assimilate changes in the perceptual states or in the information that other individuals are exposed to. In a 1992 paper, Seyfarth and Cheney already detailed the experiments that lead them to this conclusion, but they also suspected it need not be the case for other species, such as chimpanzees. The psychological capacities of animals demand careful distinctions and observations case by case.

Although animals are clearly sensitive to the presence or lack of an audience, this fact does not prove that they are also sensitive to their audience's state of mind. Moreover, considerable evidence suggests that animals cannot recognize the distinction between an ignorant audience and a knowledgeable one. Roosters and vervet monkeys, for instance, continue to give alarm calls long after their companions have seen a predator and made their escape. [...].

Research on chimpanzees suggests that these apes, unlike monkeys, may possess a rudimentary theory of mind. [...].

But at the same time, the scientific literature contains an impressive number of cases in which chimpanzees have been observed to deceive others in several different contexts and by an extraordinary variety of gestures, postures and facial expressions. By their number and variety such anecdotes gain in persuasive power and suggest at least the possibility of a theory of mind in apes. (Seyfarth and Cheney 1992, 126-8).

The question of chimpanzees being aware or not of conspecifics' beliefs was explicitly raised in Premack and Woodruf's 1978 classic paper "Does the chimpanzee have a theory of mind?." Many conceptual and empirical proposals have followed. Among the first, Bermúdez transferred Davidson's linguistic approach to second order beliefs: language would not be required for direct belief and concept possession, but it would for beliefs about beliefs (Andrews 2015, 142-145). Among the second, I will only mention Lurz' presentations of the state of art and optimistic agnosticism (Lurz 2011; Lurz and Krachun 2011; Lurz et al 2014; also Andrews 2012; Fagan 2016; Spaulding 2018).

To conclude, I would like to resume the conceptual alternatives of concept denial and ascription to animals by Davidson and Allen from the viewpoint of the empirically attested psychological and behavioral capacities of vervet monkeys. As we have seen, the individuals of this species (1) issue different alarm calls for different predators, (2) make mistakes, (3) detect them and refine their calls without novel perceptions, and (4) are unaware of conspecifics' beliefs, since they do not adapt their alarm calls to the evidence of other monkeys' seeing or not the predators. According to Davidson, vervet monkeys cannot possess concepts because they lack language. According to Allen, the first three capacities make better sense if we postulate a psychological element beyond perception that is operating in the minds of these language-less creatures. He proposes to conceive of it as an animal concept.

As Allen points out, ethology offers observations of the behavior of different animal species that can be viewed, with different degrees of difficulty, in light of these criteria. First, it can be empirically examined whether certain animals are able to distinguish a class of objects from other classes; second, whether they are able to 
detect their own errors. But, third, only if there seems to be sufficient evidence that the correction of the initial capacity can only be explained by the taking into account of previous errors, and not by the presence of any additional perceptual element, will we be entitled to speak of animal conceptual content. What is decisive is that the reason why Allen argues for concept attribution to animals is this specific capacity for error detection and behavior adjustment, should it be empirically tested, which cannot be explained by perceptual experiences. The fundamental distinction on which Allen's proposal is based is the venerable epistemological distinction between perception and concept, that he adapts and applies to animal behavior. Allen himself stresses that conditions (ii) and (iii) have not been thoroughly investigated, but provide the basis for empirical research that can contradict the thesis that animals have no beliefs or concepts (Allen 1999, 38; see also 1991, 2013).

Finally, I should like to stress that empirical observations do not strictly refute Davidson's analysis, but rather invite us to revise and refine his and other conceptual reasoning. This is an example of "constant calibration of concepts and observations," to put it in Andrews' words I quoted at the outset of this paper. The empirical findings about vervets' error-adjusting behavior are better understood and accounted for with a notion of speechless animal concepts and beliefs. On the other hand, although Allen's criteria are exclusively intended for first-order intentional cognition, I would suggest that they can be naturally generalized to second order cognition. The fact that vervet monkeys do not correct their behavior in light of their acquaintance with other monkeys' perceptions seems to allow the further conclusion that they lack beliefs about others' beliefs, that is, the capacity of reading or at least taking into account the mind of others.*

* I am very grateful to an anonymous referee for their insightful comments and demands of clarification.

Funding I am also grateful for funding to Universidad Complutense / Comunidad de Madrid, project number PR65/19-22446.

Data Availability NA

Code Availability NA

Declaration

Conflicts of interest/Competing interests The author has no relevant financial or non-financial interests to disclose.

Open Access This article is licensed under a Creative Commons Attribution 4.0 International License, which permits use, sharing, adaptation, distribution and reproduction in any medium or format, as long as you give appropriate credit to the original author(s) and the source, provide a link to the Creative Commons licence, and indicate if changes were made. The images or other third party material in this article are included in the article's Creative Commons licence, unless indicated otherwise in a credit line to the material. If material is not included in the article's Creative Commons licence and your intended use is not permitted by statutory regulation or exceeds the permitted use, you will need to obtain permission directly from the copyright holder. To view a copy of this licence, visit http://creativecommons.org/licen ses/by/4.0/. 


\section{References}

Allen, C. (1999). Animal concepts revisited: the use of self- monitoring as an empirical approach. Erkenntnis, 51(1), 33-40.

Allen, C. (2013). The geometry of partial understanding. American Philosophical Quarterly, 50(3), $249-262$.

Allen, C. (2014). Models, mechanisms, and animal minds. Southern Journal of Philosophy, 52, 75-97.

Allen, C. (2017). On (not) defining cognition. Synthese: An International Journal for Epistemology, Methodology and Philosophy Science, 194(11), 4233-4249.

Allen, C., \& Bekoff, M. (1997). Species of mind: the philosophy and biology of cognitive ethology. Cambridge: MIT Press.

Andrews, K. (2002). Interpreting autism: A critique of Davidson on thought and language. Philosophical Psychology, 15, 317-332.

Andrews, K. (2012). Do apes read minds? Toward a new folk psychology. Cambridge, London: MIT Press.

Andrews, K. (2014). Colin Allen's philosophy of animal minds. American Philosophical Association Newsletters: Philosophy and Computers, 13(2), 7-8.

Andrews, K. (2015). The animal mind. An introduction to the philosophy of animal cognition. London / New York: Routledge.

Andrews, K. (2016). Animal cognition. In Stanford Encyclopedia of Philosophy.

Bekoff, M., Allen, C., \& Burghardt, G. M. (Eds.). (2002). The cognitive animal: empirical and theoretical perspectives on animal cognition. Cambridge, MA: MIT Press.

Chadha, M. (2007). No speech, never mind! Philosophical Psychology, 20(5), 641-657.

Cheney, D., \& Seyfarth, R. (1990). Attending to behaviour versus attending to knowledge: examining monkeys' attribution of mental states. Animal Behaviour, 40(4), 742-753.

Cheney, D., \& Seyfarth, R. (1996). How monkeys see the world: inside the mind of another species. Chicago: University of Chicago Press.

Cheney, D., \& Seyfarth, R. (2007). Baboon metaphysics: the evolution of a social mind. Chicago: University Of Chicago Press.

Davidson, D. (1975). Thought and talk. In D. Davidson, Inquiries into truth and interpretation (pp. 155170). Oxford: Clarendon Press, 1984.

Davidson, D. (1982). Rational animals. Dialectica: International Journal of Philosophy of Knowledge, 36(4), 317-327.

Davidson, D. (1999). The emergence of thought. Erkenntnis, 51(1), 7-17.

Fagan, T. (2016). Animal mindreading and the Principle of conservatism. The Southern Journal of Philosophy, 54(2), 189-208.

Gensini, S. (2018). Appunti su semiotica ed etologia. Un dialogo (parzialmente) interrotto. Reti, Saperi, Linguaggi. Italian Journal of Cognitive Sciences, 7(1), 97-110.

Glock, H.-J. (2017). Animal rationality and belief. In Andrews, K. \& Beck. J. (Eds.). The Routledge handbook of philosophy of animal minds (pp. 89-99). Abingdon / New York: Routledge.

Lurz, R. W. (2011). Mindreading animals: the debate over what animals know about other minds. Cambridge: MIT Press.

Lurz, R. W., \& Krachun, C. (2011). How could we know whether nonhuman primates understand others' internal goals and intentions? Solving Povinelli's problem. Review of Philosophy and Psychology, 2(3), 449-481.

Lurz, R. W., Kanet, S., \& Krachun, C. (2014). Animal mindreading: a defense of optimistic agnosticism. Mind and Language, 29(4), 428-454.

Martínez-Freire, P. (2008). El futuro de la filosofía de la mente. Ludus Vitalis: Revista de Filosofía de las Ciencias de la Vida, 16(29), 187-190.

Martínez-Freire, P. (2009). Análisis conceptual y conocimiento experimental en filosofía de la mente. Ludus Vitalis: Revista de Filosofia de las Ciencias de la Vida, 17(32), 443-446.

Nagel, T. (1974). What is it like to be a bat? The Philosophical Review, 83(4), 435-450.

Premack, D., \& Woodruf, G. (1978). Does the chimpanzee have a theory of mind? Behavioral and Brain Sciences, 1(4), 515-526. https://doi.org/10.1017/S0140525X00076512.

Seyfarth, R., \& Cheney, D. (1992). Meaning and mind in monkeys. Scientific American, 267(6), 122-128. https://doi.org/10.1038/scientificamerican1292-122.

Seyfarth, R., \& Cheney, D. (2015). The evolution of concepts about agents: or what do animals recognize when they recognize an agent? In E. Margolis, Laurence, S (Ed.), The conceptual mind: new directions in the study of concepts (pp. 57-76). Cambridge: MIT Press. 
Seyfarth, R., Cheney, D., \& Marler, P. (1980). Vervet monkey alarm calls: Semantic communication in a free-ranging primate. Animal Behaviour, 28, 1070-1094.

Spaulding, S. (2018). Mindreading beyond belief: a more comprehensive conception of how we understand others. Philosophy Compass, 13(11), e1-e11.

Stephan, A. (1999a). Introduction: Animal beliefs, concepts, and communication. Erkenntnis, 51(1), 1-6.

Stephan, A. (1999b). Are animals capable of concepts? Erkenntnis, 51(1), 79-92.

Publisher's Note Springer Nature remains neutral with regard to jurisdictional claims in published maps and institutional affiliations. 